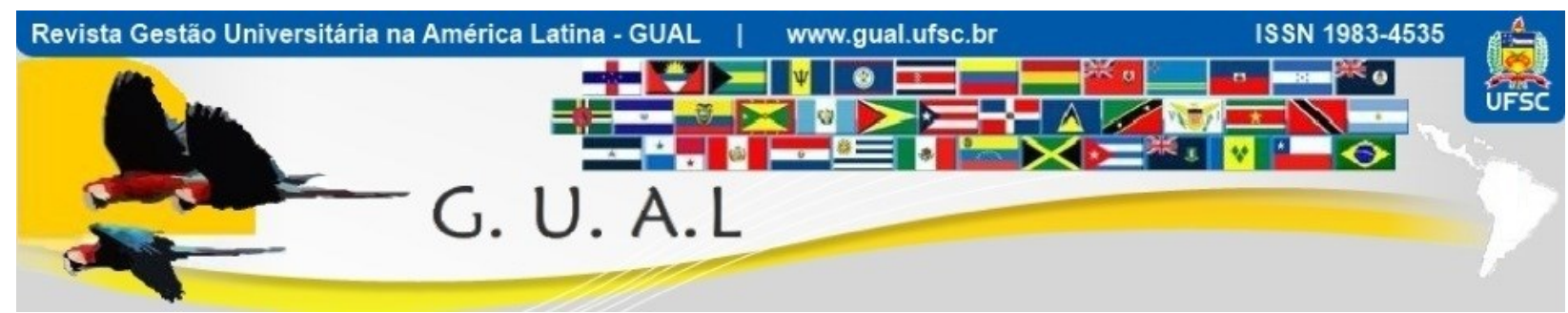

DOI: http://dx.doi.org/10.5007/1983-4535.2020v13n1p180

\title{
EFICÁCIA DOS PROCESSOS DE PLANEJAMENTO EM INSTITUICCÕES DE ENSINO SUPERIOR PRIVADAS: AVALIAÇÃO DO EFEITO DA FORMALIZAÇÃO DO PROCESSO DE PLANEJAMENTO
}

\section{EFFICACY OF PLANNING PROCESSES IN PRIVATE HIGHER EDUCATION INSTITUTIONS: EVALUATION OF THE EFFECT OF FORMALIZATION OF THE PLANNING PROCESS}

\author{
Valdeci Ferreira dos Santos, Mestre \\ https://orcid.org/0000-0003-0638-1599 \\ valdeci.santos5@bol.com.br \\ Fundação Mineira de Educação e Cultura | Programa de Doutorado e Mestrado em Administração \\ Belo Horizonte | Minas Gerais | Brasil \\ Ronielton Rezende Oliveira, Doutor \\ http://orcid.org/0000-0002-7551-065X \\ ronielton@fumec.edu.br \\ Fundação Mineira de Educação e Cultura | Programa de Doutorado e Mestrado em Administração \\ Belo Horizonte | Minas Gerais | Brasil \\ Luiz Antônio Antunes Teixeira, Doutor \\ http://orcid.org/0000-0002-0871-0301 \\ lantonio@fumec.edu.br \\ Fundação Mineira de Educação e Cultura | Programa de Doutorado e Mestrado em Administração \\ Belo Horizonte | Minas Gerais | Brasil
}

Recebido em 21/dezembro/2018

Aprovado em 15/outubro/2019

Publicado em 02/janeiro/2020

Sistema de Avaliação: Double Blind Review

Esta obra está sob uma Licença Creative Commons Atribuição-Uso. 


\title{
RESUMO
}

As Instituições de Ensino Superior (IES) passam por um aumento na competitividade que reflete no aumento do número de cursos, vagas e surgimento de novas IES. O estudo analisa a percepção dos responsáveis pelo planejamento das IES privadas da Região Metropolitana de Belo Horizonte, quanto aos fatores que antecedem o sistema de planejamento e suas dimensões de eficácia. A análise de dados utilizou a Partial Least Squares Structural Equation Modeling para avaliar a formalização como moderador do processo de planejamento e sua eficácia. A cobertura do sistema de planejamento, a resistência ao planejamento, a atenção a eventos internos, a atenção a eventos externos, a utilização de técnicas de planejamento e os recursos alocados no planejamento explicam aproximadamente $36 \%$ da eficácia, que por sua vez, implica em cerca de $81 \%$ da capacitação do sistema gerencial, em $56 \%$ do desempenho relativo à concorrência e em $26 \%$ do cumprimento dos objetivos do planejamento.

Palavras-chave: Educação. Planejamento Estratégico. Gestão Acadêmica. Eficácia. IES.

\begin{abstract}
The Higher Education Institutions (HEI) are experiencing an increase in competitiveness, which reflects the increase in the number of courses, vacancies and the emergence of new HEI. The study examines the perception of those responsible for planning of private HEI in the Metropolitan Region of Belo Horizonte in Brazil, about the factors leading up to the planning system and its efficacy dimensions. Data analysis used Partial Least Squares Structural Equation Modeling to evaluate formalization as moderator of the planning process and its efficacy. The coverage of the planning system, the resistance to planning, the attention to internal events, the attention to external events, the use of planning techniques and the resources in planning explain approximately $36 \%$ of the efficacy, which in turn, implies about $81 \%$ of the capacity of the management system, $56 \%$ of the performance relative to the competition and $26 \%$ of the fulfillment of the planning objectives.
\end{abstract}

Keywords: Education. Strategic Planning. Academic Management. Efficacy. HEI. 


\section{INTRODUÇÃO}

As características das Instituições de Ensino Superior (IES) determinam a sua estrutura, funcionamento e principalmente o modelo de gestão a ser adotado (MEYER JR.; SERMANN; MANGOLIM, 2004). Estas instituições são consideradas organizações complexas pelos seus objetivos prolixos e imprecisos, tecnologia abstrusa, existência de grupos de interesses distintos na sua estrutura, características específicas de sua clientela, do próprio meio acadêmico e da potencialidade da influência de fatores externos (MEYER JR.; MEYER, 2011).

A discussão acerca do planejamento estratégico vem de longa data. As primeiras proposições estão na década de 1960 com o modelo da corrente principal de George Steiner e a matriz produto/mercado de Igor Ansoff, tendo sequência com o diamante de Michael Porter nos anos 1980 e os 5P's (plano, pretexto, padrão, posição e perspectiva) para compreensão da estratégia de Henry Mintzberg na década de 1990. O fato é que entre as ferramentas de gestão, o planejamento estratégico é o mais utilizado pelas organizações (KICH; PEREIRA, 2011).

Há uma lacuna na prática da gestão estratégica em IES que separa o que é planejado formalmente pelos gestores, do que realmente é executado nas estratégias, o que pode ser atribuído à especificidade desse tipo de organização, pois dificilmente os modelos tradicionais de gestão terão sucesso nas IES (MEYER JR.; PASCUCCI; MANGOLIN, 2012). Por isso, os gestores das IES devem ser capazes de compreender e atuar considerando tanto o ambiente interno, quanto o externo, de forma a estarem preparados para lidar com as questões que ultrapassam a esfera acadêmica e envolvem a sobrevivência no mercado (FIDELIS; BARBOSA, 2012). Esse panorama demanda que as IES revejam suas políticas e práticas de gestão, buscando mais eficiência para possibilitar a consecução de seus objetivos que levem a obtenção de vantagem competitiva para garantir sua sobrevivência (DIAS; SANTOS; BEIRUTH, 2016).

A verificação é que no início de 2017 existiam 2.760 IES no Brasil. Desse montante, 2.448 fazem parte do setor privado e dessas, 1.262 funcionam com fins lucrativos (MEC, 2017). Tendo em vista o contexto em que as IES estão inseridas e a adoção do planejamento estratégico como direcionador de suas ações, surge a necessidade de aprofundamento sobre o sistema de planejamento nas IES privadas, a fim de elucidar aspectos relacionados às suas características, formalização e eficácia, de acordo com a percepção de gestores responsáveis 
pelo planejamento e pessoas ligadas às atividades de apoio ao planejamento nas IES (SANTOS, 2017).

No cenário internacional as pesquisas prévias sugerem que o planejamento estratégico e a ação dos gestores constitui um critério de sustentabilidade para IES (BIELER; MCKENZIE, 2017; FARINHA; AZEITEIRO; CAEIRO, 2017; HU; CHEN; QIN, 2017; SAUROMBE; BARKHUIZEN; SCHUTTE, 2017; BALTARU; SOYSAL, 2018). Por outro lado, as constantes mudanças na economia brasileira vêm testando as habilidades e as competências dos gestores. Sob essa ótica justifica-se o presente estudo, pois as IES privadas frente ao mercado competitivo, nacional e regional, além de desenvolver seus processos de planejamento, também necessitam compreender o quão eficaz são suas práticas de gestão a fim de garantir a própria sobrevivência.

O esquema conceitual de Ramanujam e Venkatraman (1987) foi adaptado neste estudo para teste empírico sobre três indagações predominantes. A primeira, se refere às influências das características dos processos de planejamento das IES sobre a eficácia destes processos. A segunda, se refere à formalização do sistema de planejamento como moderador na relação entre as características dos processos de planejamento das IES e a eficácia destes processos. A terceira, se refere à influência da eficácia observada em função dos processos de planejamento das IES e suas características nas dimensões consequentes da eficácia. Portanto, o objetivo deste estudo é analisar a percepção dos responsáveis pelo planejamento das IES privadas da Região Metropolitana de Belo Horizonte, quanto aos fatores que antecedem o sistema de planejamento e suas dimensões de eficácia.

\section{REVISÃO DE LITERATURA}

Esta seção aborda a formalização que incide na relação entre os antecedentes dos processos de planejamento e os consequentes da eficácia, a saber: cumprimento dos objetivos do planejamento, capacitação do sistema gerencial e desempenho relativo a concorrência.

\subsection{FORMATAÇÃO}

As organizações que instituem processos formais para realizar seu planejamento estratégico obtêm melhor desempenho do que aquelas que não implementam tais processos, pois elas adquirem conhecimento sistemático a respeito das variáveis internas e externas que afetam seu funcionamento de forma a otimizar e alinhar a organização com seu ambiente 
(LORANGE, 1979). Com isso, o processo formal de planejamento é a capacidade da organização em facilitar a coleta e análise dos dados que levam a uma informação pertinente à manutenção de um ambiente organizacional estável e produtivo (ARMSTRONG, 1982).

A formalização do processo de planejamento é vital para que dele possam ser estabelecidos benefícios. As evidências sugerem que as organizações possuem determinado grau de formalização nos seus sistemas de planejamento, que pode ser: inexistente, informal ou com baixo grau; com algum grau; ou formalizado (ESTOLANO, 2002a). A compreensão para este estudo é que quando inexistente, significa que toda e qualquer atividade na organização é realizada ao acaso, muitas vezes, como uma forma reativa aos eventos ambientais. O baixo grau indica que algumas ações seguirão rotinas pré-estabelecidas, contudo, essas estão vinculadas a departamentos e tendem a ser realizadas de acordo com a percepção de utilidade das pessoas. Com algum grau, abrange as áreas funcionais e assume uma característica repetitiva sobre contextos de planejamento determinados. Sendo formalizado, está sobre a égide da organização e é executado como uma função de governança e intenções estratégicas.

Nesta direção, a hipótese H1 é que a formalização dos processos de planejamento das IES atua como moderador da influência dos processos de planejamento na eficácia destes processos. A Figura 1 ilustra o efeito moderador da formalização sobre as dimensões do sistema de planejamento com sua eficácia.

Figura 1 Modelo Hipotético

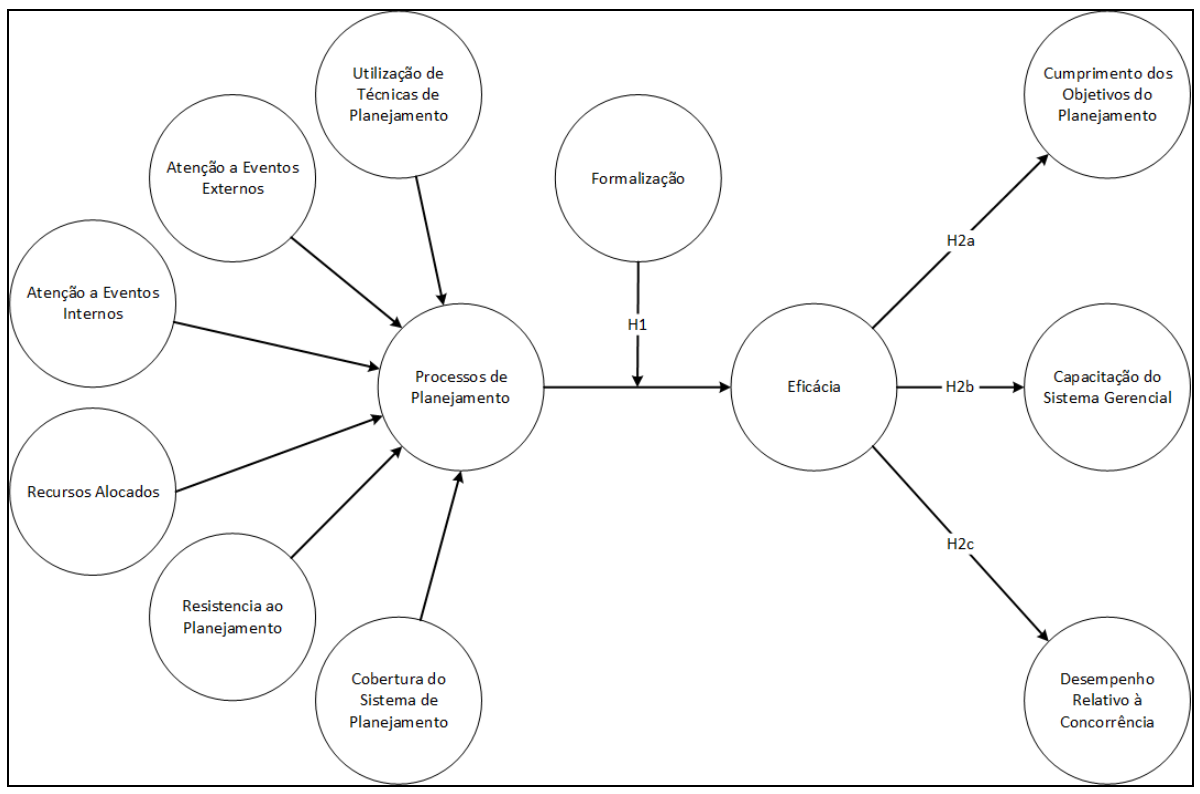

Fonte: Elaborado pelos autores. 


\subsection{ANTECEDENTES DOS PROCESSOS DE PLANEJAMENTO E CONSEQUENTES DA EFICÁCIA}

Neste estudo não há diferenciação entre o planejamento funcional e o planejamento estratégico, pois considera-se que ambos têm a finalidade de preparar a organização para lidar com os eventos futuros. O esquema conceitual de Ramanujam e Venkatraman (1987) é adequado para a analisar o comportamento dos processos de planejamento em sua relação com os consequentes da eficácia nas organizações. Este modelo baseia-se em seis características do sistema de planejamento, sendo elas: utilização de técnicas de planejamento, atenção a eventos externos, atenção a eventos internos, recursos alocados, resistência ao planejamento e cobertura do sistema de planejamento para entender os efeitos da eficácia do planejamento, no cumprimento dos objetivos do planejamento, na capacitação do sistema gerencial e no desempenho relativo a concorrência (RAMANUJAM; VENKATRAMAN, 1987). A Figura 2 apresenta o diagrama que vincula as dimensões do sistema de planejamento com sua eficácia.

Figura 2 Interação do Sistema de Planejamento com sua Eficácia

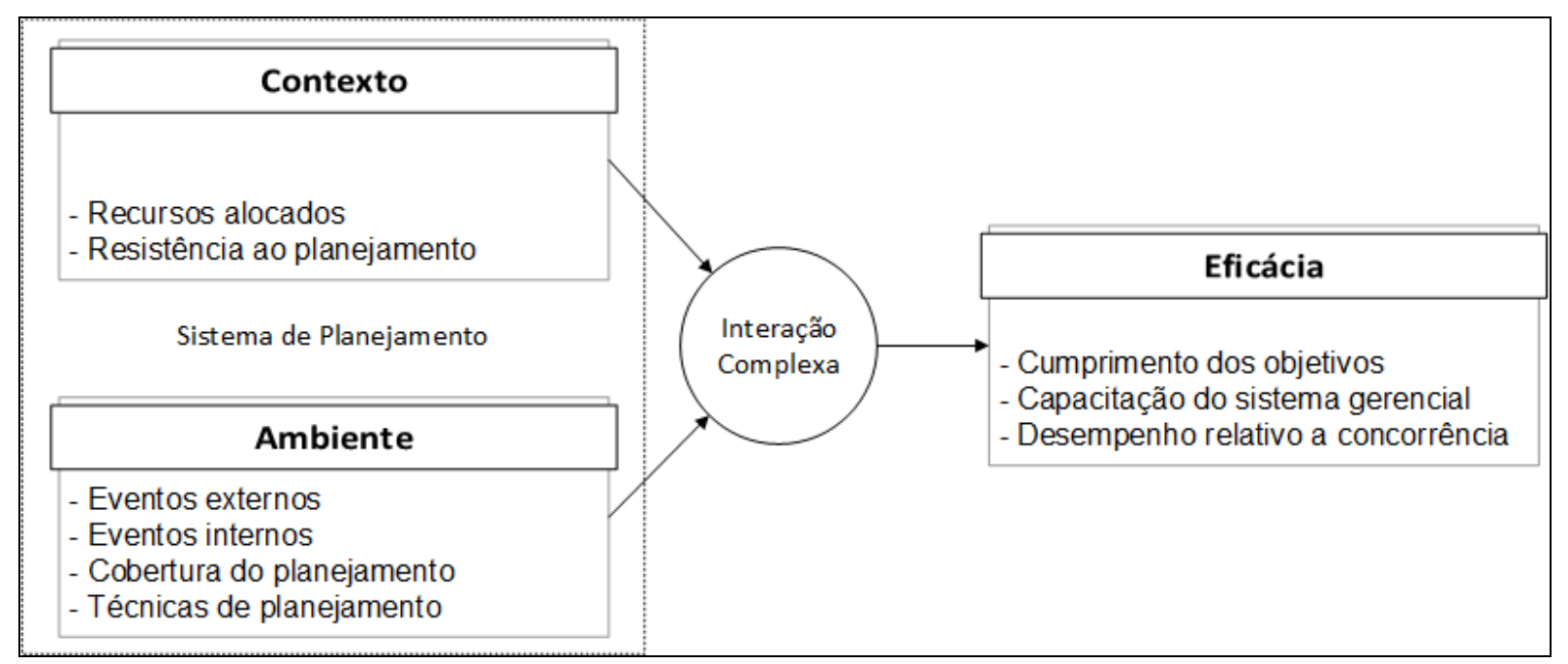

Fonte: Adaptado de Ramanujam e Venkatraman (1987, p. 37).

A utilização de técnicas de planejamento é a ênfase para estruturar soluções para os problemas estratégicos da organização. Como um processo de apoio é observado como um fator de sucesso que permite maior compreensão e aceitação do processo de planejamento. Há uma variedade de ferramentas e técnicas, que podem ser utilizadas pelas organizações para auxiliar nos processos de planejamento, por exemplo, análise de forças, fraquezas, oportunidades e ameaças (SWOT), técnicas de portfólio, modelos financeiros, zero-based 
budgeting, balanced scorecard (BSC), delphi, forecasting analysis, reengenharia, técnicas de custeio, qualidade total, just in time, kanban, seis sigmas, entre outras que sistematizam e flexibilizam as ações dos gestores com a intenção de desenvolver conhecimento interno à organização, para uniformizar políticas e discursos (RAMANUJAM; VENKATRAMAN; CAMILLUS, 1986; RAMANUJAM; VENKATRAMAN, 1987; ESTOLANO, 2002a; 2002b; PARANJAPE; ROSSITER; PANTANO, 2006).

A atenção a eventos externos está na ênfase dada ao monitoramento das tendências ambientais, por meio da análise das ameaças e oportunidades advindas do ambiente externo, uma vez que esse é um fator preponderante para o processo de planejamento. As organizações devem estar atentas aos eventos que podem afetar sua estratégia, bem como aptas para responder corretamente às mudanças do ambiente externo à organização, para de forma adequada se prepararem e se protegerem do contexto ambiental na qual estão inseridas, por exemplo, aspectos de negócio, condições econômicas do mercado, eventos mundiais, evolução tecnológica, tendências de fornecedores, preferências dos consumidores e assim por diante (PORTER, 1980; RAMANUJAM; VENKATRAMAN, 1987; ESTOLANO, 2002a; 2002b; TERENCE, 2002).

A atenção a eventos internos incide sobre os fatores organizacionais, desempenho passado e análise de pontos fortes e fracos da organização. O que deve acontecer é um inventário que identifique os recursos e habilidades para a boa execução do plano estratégico. A intenção é de conhecer os fatores críticos de sucesso que favoreçam ou dificultam a implementação das ações estratégicas que visam alcançar os objetivos e as metas, principalmente, porque as competências e as capacidades constituem os diferenciais de uma organização para que o planejamento estratégico seja eficiente (PORTER, 1980; LEIDECKER; BRUNO, 1984; RAMANUJAM; VENKATRAMAN，1987; ESTOLANO, 2002a; 2002b; TERENCE, 2002).

Os recursos alocados implicam no comprometimento organizacional com o processo de planejamento ao fornecer uma estrutura apropriada, em termos de número de pessoas envolvidas com a atividade de planejamento, estrutura física, nível de envolvimento da alta direção, entre outras que favoreçam o planejamento estratégico, geralmente, sobre uma modificação na estrutura organizacional, que a partir de um setor específico, tenha foco neste processo de gestão. A organização de forma conveniente e apropriada deve utilizar os recursos para as atividades de planejamento e apoio ao planejamento, porque, ainda que os 
recursos tangíveis e intangíveis, como os recursos financeiros, humanos e infraestrutura estejam sendo bem utilizados, existe a possibilidade da eficácia do processo ser questionada (RAMANUJAM; VENKATRAMAN， 1987; CHAKRAVARTHY; LORANGE， 1991; STEINER, 1991; ESTOLANO, 2002a; 2002b).

A resistência ao planejamento consiste no conjunto de ações que dificultam este processo de gestão, seja por parte da alta gerência, seja por parte dos funcionários. A questão central é que a organização deve estar atenta e ser capaz de eliminar os focos de resistência, assim como mediar os conflitos e ordenar os esforços em todos os níveis da organização para colaboração das pessoas em prol dos objetivos estratégicos, posto que tanto a implementação, quanto a execução da estratégia, geram mudanças na organização, podendo atingir desde atividades, departamentos até a organização como um todo em seus diferentes níveis (RAMANUJAM; VENKATRAMAN, 1987; STEINER, 1991; ESTOLANO, 2002a; 2002b; BETHLEM, 2004).

A cobertura do sistema de planejamento está vinculada a extensão que recai nas diferentes áreas funcionais com vista a integrar os requisitos de negócios numa perspectiva de gestão geral que seja uniforme, especialmente, porque uma das funções do planejamento é consolidar e coordenar as informações geradas pelas demais áreas da organização para atingir os objetivos e as metas estratégicas. O foco deve estar na integração das diferentes áreas funcionais e suas distintas competências que favorecem o processo de planejamento estratégico, em relação ao apoio político, fornecimento de dados e em termos de recursos humanos (HITT; IRELAND; PALIA, 1982; RAMANUJAM; VENKATRAMAN, 1987; ESTOLANO, 2002a; 2002b).

O cumprimento dos objetivos de planejamento pode ser compreendido por diversas perspectivas, que incluem, possibilitar às organizações minimizar as incertezas no seu processo decisório, assim como se posicionarem de forma competitiva frente à concorrência; reduzir as incertezas, influenciando diretamente a tomada de decisão na organização, assim como nos seus resultados; integrar a missão, visão, valores, objetivos, metas, políticas e sequências de ação da organização de forma global e alinhada; possibilitar à organização o alcance de sua visão de futuro por meio da ordenação das ideias e ações; e melhorar a integração entre os setores da organização devido ao incentivo à busca por objetivos comuns (RAMANUJAM; VENKATRAMAN, 1987; DRUCKER, 1998; SAMPAIO, 2002; 
ESTOLANO, 2002b; MINTZBERG et al., 2005; ESTRADA; ALMEIDA, 2007; KICH; PEREIRA, 2011).

A capacitação do sistema gerencial são as ações que levam gestores e pessoal de apoio ao planejamento, ao aprendizado e desenvolvimento de competências durante o processo de planejamento. Isto proporciona a essas pessoas um ponto de vista diferenciado dos negócios, bem como a habilidade de atuar em diferentes áreas e contextos de gestão. O que importa é a evolução do corpo gerencial e técnico da organização de forma que o conhecimento adquirido contribua para a continuidade dos negócios e isso, por exemplo, pode implicar na capacidade de antecipar-se a eventos para identificar potenciais crises, adaptar-se a cenários desafiadores, integrar funções de gestão e operações, entre outras (RAMANUJAM; VENKATRAMAN; CAMILLUS, 1986; RAMANUJAM; VENKATRAMAN, 1987; VIZEU; GONÇALVES, 2010; ESTOLANO, 2002a).

O desempenho relativo à concorrência envolve uma série de aspectos, como, disputa de posições entre organizações de um setor, por meio da concorrência de preços, publicidade, introdução de novos serviços, aumento na qualidade dos serviços ou das garantias aos compradores, entre outros. Sendo que uma intenção do processo de planejamento é melhorar o posicionamento da organização frente seus concorrentes, precisamente, quando o planejamento estratégico capacita os gestores para buscar o desempenho no curto prazo, e evoluir as perspectivas de longo prazo em relação a vantagem competitiva, de modo a proporcionar uma melhoria de posicionamento no mercado (PORTER, 1986; RAMANUJAM; VENKATRAMAN; CAMILLUS, 1986; RAMANUJAM; VENKATRAMAN, 1987; VELIYATH, 1992; ESTOLANO, 2002a).

Sobre esses argumentos, a hipótese $\mathbf{H 2}$ é que os consequentes da eficácia, cumprimento dos objetivos do planejamento (H2a), capacitação do sistema gerencial (H2b) e desempenho relativo à concorrência $(\mathbf{H 2 c})$ são influenciados positivamente pela eficácia observada em função dos processos de planejamento.

\section{METODOLOGIA}

A pesquisa tem abordagem quantitativa, natureza descrita e utilizou do procedimento survey através de formulário eletrônico. Os enunciados foram elaborados para este estudo. A escala, no pré-teste e coleta de dados, foi Likert (discordo totalmente; discordo; não concordo nem discordo; concordo; concordo totalmente). As questões são apresentadas na Figura 3. 


\section{EFICÁCIA DOS PROCESSOS DE PLANEJAMENTO EM INSTITUIÇÕES DE ENSINO SUPERIOR PRIVADAS: AVALIAÇÃO DO EFEITO DA FORMALIZAÇÃO DO PROCESSO DE PLANEJAMENTO DOI: http://dx.doi.org/10.5007/1983-4535.2020v13n1p180}

\section{Figura 3 Enunciados}

Formalização (FORM)

[form_01] A missão, visão, objetivos estratégicos, metas e valores da IES são dispostos em documento escrito. [form_02] A missão, visão, objetivos estratégicos, metas e valores da IES são amplamente transmitidos para todos os seus funcionários. [form_03] A missão, visão, objetivos estratégicos e valores da IES são conhecidos pelos seus concorrentes, clientes e fornecedores.

Utilização de Técnicas de Planejamento (TECN)

[tecn_01] O sistema de planejamento da IES utiliza técnicas baseadas no orçamento com base zero.

[tecn_02] O sistema de planejamento da IES utiliza técnicas que relacionam seus valores institucionais

[tecn_03] A IES utiliza técnicas de planejamento baseadas na análise das partes interessadas.

[tecn_04] O planejamento da IES utiliza técnicas baseadas na análise de cenários.

[tecn_05] O planejamento da IES faz uso de técnicas baseadas na previsão e análise de tendências.

Atenção a Eventos Externos (EVEX)

[evex_01] O planejamento estimula a IES a estar sempre atenta às condições econômicas e comerciais do ambiente onde está inserida.

[evex_02] O planejamento estimula a IES a estar sempre atenta às tendências de competitividade.

[evex_03] O planejamento estimula a IES a estar sempre atenta às tendências tecnológicas.

Atenção a Eventos Internos (EVIN)

[evin_01] O planejamento possibilita à IES conhecer suas capacidades internas.

[evin_02] O planejamento contribui para que a IES tenha conhecimento sobre o seu desempenho passado.

[evin_03] O planejamento possibilita à IES conhecer as razões das suas falhas passadas.

$$
\text { Recursos Alocados (RECU) }
$$

[recu_01] O local físico disponibilizado para o exercício das atividades de planejamento é adequado.

[recu_02] A quantidade de funcionários para dedicar exclusivamente às atividades do planejamento é suficiente para execução das tarefas.

[recu_03] O tempo médio despendido pelo executivo na atividade de planejamento é suficiente para o seu bom andamento.

$$
\text { Resistencia ao Planejamento (RESI) }
$$

[resi_01] O planejamento está em evidência, sendo considerada uma importante ferramenta de gestão na IES.

[resi_02] Os pró-reitores, diretores e coordenadores são envolvidos e comprometidos com o planejamento da IES.

[resi_03] A alta administração valoriza o exercício de planejamento e atribui os resultados da IES à utilização desta ferramenta.

Cobertura do Sistema de Planejamento (CPLA)

[cpla_01] O sistema de planejamento abrange a função de marketing.

[cpla_02] A função de finanças é coberta pelo sistema de planejamento.

[cpla_03] O sistema de planejamento da IES abrange a função de gestão de pessoas.

[cpla_04] A função de compras e aquisições na IES é coberta pelo sistema de planejamento.

[cpla_05] O sistema de planejamento da IES abarca a função de desenvolvimento tecnológico.

Cumprimento dos Objetivos do Planejamento (OBJT)

[objt_01] O sistema de planejamento cumpre o objetivo de melhorar o desempenho da IES em curto prazo.

[objt_02] O sistema de planejamento cumpre o objetivo de melhorar o desempenho da IES em longo prazo.

[objt_03] O sistema de planejamento cumpre o seu objetivo de avaliar alternativas com base nas informações mais relevantes.

[objt_04] O sistema de planejamento cumpre o seu objetivo de evitar problemas.

$$
\text { Capacitação do Sistema Gerencial (CAPC) }
$$

[capc_01] O sistema de planejamento é capaz de proporcionar flexibilidade para adaptação às mudanças imprevistas.

[capc_02] O sistema de planejamento é capaz de possibilitar a identificação de novas oportunidades de negócios.

[capc_03] O sistema de planejamento se mostra apropriado na sua função de identificar áreas problemáticas.

[capc_04] O sistema de planejamento se mostra adequado quanto à capacidade de motivar o corpo gerencial.

[capc_05] O sistema de planejamento se mostra adequado como meio de geração de novas ideias.

[capc_06] O sistema de planejamento se mostra capaz de viabilizar a comunicação das expectativas da alta gerência ao longo da IES.

[capc_07] O sistema de planejamento se mostra capaz de promover a aprendizagem organizacional. 
[conc_01] Quanto ao crescimento no número de alunos, o desempenho da IES se mostra superior ao de seus concorrentes.

[conc_02] Quanto à participação de mercado, o desempenho da IES se mostra superior ao de seus concorrentes.

[conc_03] Quanto ao retorno sobre o investimento, o desempenho da IES se mostra superior ao de seus concorrentes.

[conc_04] Quanto ao crescimento dos resultados em geral, o desempenho da IES se mostra superior ao de seus concorrentes.

Fonte: Elaborado pelos autores.

O sujeito na pesquisa, independente do cargo ocupado, é formado por responsáveis pelo planejamento, assim como, por funcionários, que atuam com o planejamento ou tem conhecimento sobre o sistema de planejamento nas 82 IES privadas localizadas no estado de Minas Gerais. A indicação dos respondentes foi realizada por meio de contato telefônico com as IES, sendo obtidas as informações da estrutura da equipe de planejamento com a identificação dos funcionários recomendados para responder o questionário com seus respectivos endereços de correio eletrônico, no qual foi disponibilizado o link para resposta. Não houve limitação no número de respondentes por IES.

A coleta dos dados teve duração de três meses (junho a agosto de 2017). Não foram identificados outliers na amostra de 118 respondentes, poder estatístico, software G*Power; $f$ test modelo fixo de regressão linear múltipla para aumento do $\mathrm{R}^{2} \operatorname{com} 6$ efeitos e 12 construtos; $\alpha=0,05 ; f^{2}=0,15$, efeito médio; $1-\beta=88 \%$ (COHEN, 1992; FAUL et al., 2009). A análise de dados utilizou a Partial Least Squares Structural Equation Modeling (PLS-SEM) por meio do software SmartPLS 3 (RINGLE; WENDE; BECKER, 2015), para verificar o modelo hipotético sobre o fenômeno em investigação (OLIVEIRA; MARINHO; DIAS, 2016).

\section{INSTITUIÇÕES DE ENSINO SUPERIOR EM MINAS GERAIS}

Mais de dez por cento das IES brasileiras estão localizadas no estado de Minas Gerais. 30 são públicas e 324 são privadas, dessas, 131 atuam com fins lucrativos e 193 atuam sem fins lucrativos. Na Região Metropolitana de Belo Horizonte (RMBH) são 88 IES, sendo 6 públicas e 82 privadas, nas quais, 43 tem fins lucrativos e 39 são sem fins lucrativos (MEC, 2017). Apesar da RMBH ser formada por 34 municípios, as IES estão localizadas em apenas 12 municípios, com destaque para Belo Horizonte, onde além de concentrar 100\% das IES públicas, é a sede de $64 \%$ das IES privadas, seguido de Contagem com $8 \%$, Betim com $6 \%$ e Nova lima com 5\%. A Tabela 1 apresenta o quantitativo de IES na RMBH. 
Tabela 1 Distribuição das IES na RMBH

\begin{tabular}{lcccc}
\hline \multirow{2}{*}{ Cidade } & \multirow{2}{*}{ Públicas } & \multicolumn{2}{c}{ Privadas } & \multirow{2}{*}{ Total } \\
\cline { 3 - 4 } & & Com fins lucrativos & Sem fins lucrativos & \\
\hline Belo Horizonte & 6 & 30 & 26 & 62 \\
Betim & 0 & 4 & 1 & 5 \\
Brumadinho & 0 & 1 & 0 & 1 \\
Contagem & 0 & 5 & 2 & 7 \\
Juatuba & 0 & 1 & 0 & 1 \\
Lagoa Santa & 0 & 0 & 2 & 2 \\
Nova Lima & 0 & 1 & 3 & 4 \\
Pedro Leopoldo & 0 & 0 & 1 & 1 \\
Ribeirão das Neves & 0 & 0 & 1 & 1 \\
Sabará & 0 & 0 & 2 & 2 \\
Santa Luzia & 0 & 0 & 1 & 1 \\
Vespasiano & 0 & 1 & 0 & 88 \\
\hline Total & 6 & 43 & 39 & 1 \\
\hline
\end{tabular}

Fonte: Sistema e-MEC (MEC, 2017).

A RMBH tem uma população estimada em 5.313.480 habitantes (IBGE, 2018). O estado de Minas Gerais ocupa a segunda posição na federação, sendo superado apenas pelo estado de São Paulo, quando se considera o número de alunos matriculados anualmente no ensino superior em cursos presenciais, sendo que na $\mathrm{RMBH}$, em números absolutos, foram 264.073 no ano de 2013 (SEMESP, 2015, p. 24), 275.289 no ano de 2014 (SEMESP, 2016, p. 41) e 274.937 no ano de 2015 (SEMESP, 2017, p. 59), ou seja, de 2013 a 2015, cerca de $15,33 \%$ da população da RMBH foi matriculada em algum curso de graduação.

\section{RESULTADOS E ANÁLISE}

A demografia dos dados em relação aos respondentes mostra que 50,85\% são os responsáveis diretos pelo planejamento e 49,15\% exercem atividades de apoio ao planejamento. A respeito do tempo de trabalho na IES, 19,49\% atuam de 0 a 2 anos, 30,51\% atuam de 3 a 5 anos, 11,86\% atuam de 6 a 10 anos e 38,14\% atuam a mais de 10 anos. No que se refere as características da IES, $16,10 \%$ possuem menos 500 alunos, $25,42 \%$ possuem de 500 a 1.000 alunos, $31,36 \%$ possuem de 1.001 a 5.000 alunos, $11,02 \%$ possuem de 5.001 a 10.000 alunos e $16,10 \%$ possuem mais de 10.000 alunos. Sobre a quantidade de cursos de graduação, 57,63\% tem de 1 a 5 cursos, $6,78 \%$ tem de 6 a 10 cursos, $12,71 \%$ tem de 11 a 15 cursos e $22,88 \%$ tem de 16 a 20 cursos. No mais, sobre a perspectiva dos respondentes, o sistema de planejamento pode ser observado nas IES em 11,86\% como informal ou com 
baixo grau de formalização, em 47,46\% como médio grau de formalização e em 40,68\% como alto grau de formalização.

A análise PLS-SEM ocorre em duas fases, para avaliar, primeiro, o modelo de mensuração e segundo, o modelo estrutural. Na primeira fase o questionário foi validado ao examinar a confiabilidade (alfa de Cronbach e confiabilidade composta), a validade convergente (confiabilidade do indicador e Average Variance Extracted) e a validade discriminante (critério de Fornell-Larcker e Cross Loadings) dos indicadores e construtos. Na segunda fase o modelo estrutural é analisado para compreender os efeitos e relevâncias (HENSELER; HUBONA; RAY, 2016). O efeito moderador descreve a relação entre dois construtos que não é constante, pois depende do construto moderador para modificar sua força ou direção (HAIR JR. et al., 2017). Sua operacionalização no SmartPLS foi realizada conforme indicação FORM * PLAN no modelo de mensuração apresentado na

Figura 4.

Figura 4 Modelo de Mensuração

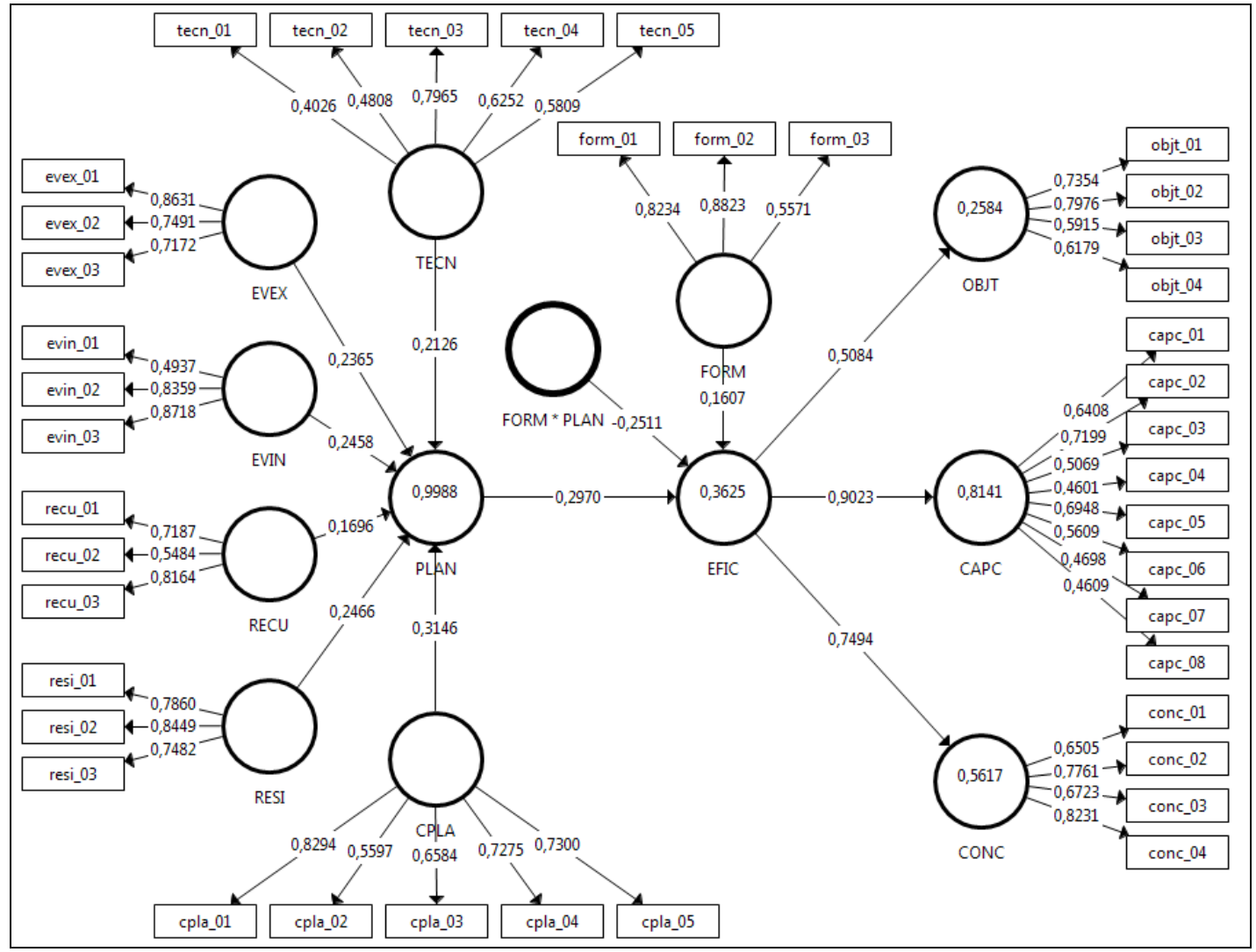

Fonte: Dados da pesquisa. 
As relações entre os construtos são estatisticamente significantes, sendo a exceção o efeito moderador, conforme apresentado no modelo estrutural exibido na Figura 5.

Figura 5 Modelo Estrutural

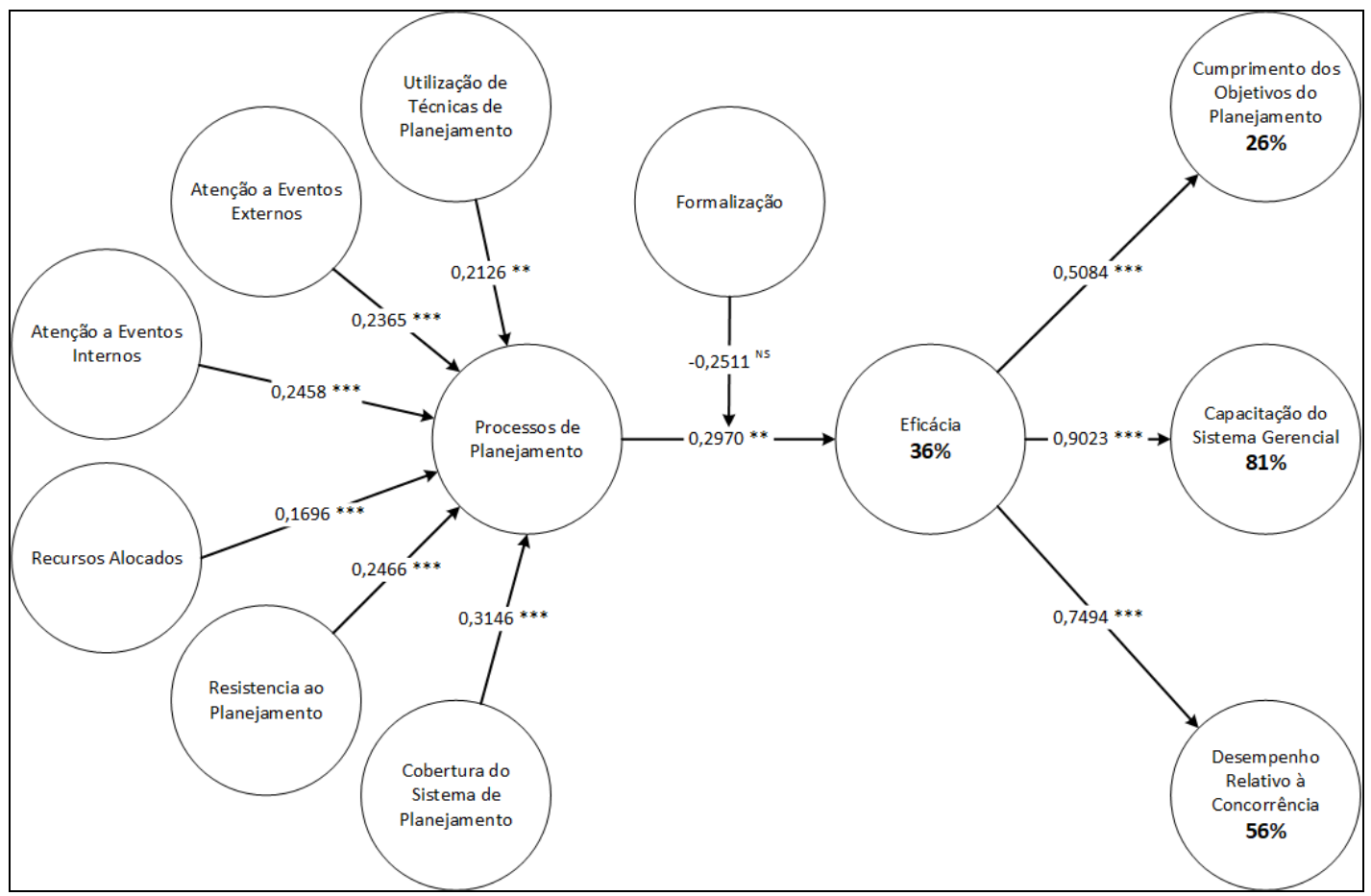

$\mathrm{NS}=$ não significante. ${ }^{* * *} \mathrm{p}<0,01 .{ }^{* *} \mathrm{p}<0,05 .{ }^{*} \mathrm{p}<0,10$.

Fonte: Dados da pesquisa.

A eficácia obteve um valor de $\mathrm{R}^{2}=0,3625$. Isso significa que os processos de planejamento e seus antecedentes são capazes de explicar a variação correspondente a aproximadamente $36 \%$ da eficácia. Também se constata que as dimensões dessa, representadas pelo cumprimento dos objetivos do planejamento $\left(\mathrm{R}^{2}=0,2584\right)$, capacitação do sistema gerencial $\left(\mathrm{R}^{2}=0,8141\right)$ e desempenho relativo à concorrência $\left(\mathrm{R}^{2}=0,5617\right)$ são explicadas respectivamente em aproximadamente $26 \%, 81 \%$ e $56 \%$. Esses resultados da capacitação do sistema gerencial como o consequente que tem maior capacidade de explicação em função dos processos de planejamento e sua eficácia, sugerem que a maior contribuição do sistema de planejamento está no aprendizado e desenvolvimento das pessoas que atuam com essa atividade, porque ela proporciona uma visão diferenciada do mundo dos negócios, bem como a habilidade de atuar em diferentes campos e contextos de gestão (VIZEU; GONÇALVES, 2010).

O desempenho relativo à concorrência é o consequente com a segunda maior capacidade de explicação em função dos processos de planejamento e sua eficácia. $\mathrm{O}$ 
cumprimento dos objetivos de planejamento é o consequente que apresenta a menor capacidade de explicação em função dos processos de planejamento e sua eficácia. A certeza é que a estratégia evolui de acordo com as mudanças e pressões causadas pela competitividade no ambiente no qual as organizações estão inseridas (CHANDLER, 1962; DRUCKER, 1998). Assim a evolução da estrutura organizacional deve seguir o desenvolvimento da estratégia, pois, essa depende daquela para prosperar, precisamente, quando observa-se que o planejamento estratégico, sobre seus diversos processos, é uma atividade contínua, composta de técnicas para avaliar o ambiente das organizações, possibilitando a elas minimizar as incertezas no seu processo decisório, para se posicionarem de forma competitiva frente à concorrência (MAINARDES; MIRANDA; CORREIA, 2011; SANTOS, 2017; SILVA; VIEIRA; SILVA, 2017; BALTARU; SOYSAL, 2018).

A formalização dos processos de planejamento das IES não exerce efeito moderador entre a influência dos processos de planejamento na eficácia destes processos, portanto, a hipótese H1 é rejeitada. Porém, $88,14 \%$ dos respondentes indicam que o sistema de planejamento é formalizado nas IES, seja como médio grau em 47,46\% das IES, seja como alto grau em 40,68\% das IES. A suposição que se põe é que o nível de formalização dos sistemas de planejamento, quando relacionado à eficácia destes sistemas ou à relação entre as características destes sistemas e a eficácia dos mesmos, tende a ser neutro, ou seja, indiferente. O que se observa é uma contradição na literatura, posto que a formalização faz parte de um rol de aspectos de racionalidade, que estão associados com a eficácia do sistema de planejamento (SEGARS; GROVER; TENG, 1998), contudo, o grau de formalização dos processos de planejamento não afeta a eficácia destes processos (ESTOLANO, 2002a). E neste estudo, os resultados se aproximam da negativa quando se sugere uma indiferença da formalização, especificamente, ao considerar que essa não tem um efeito moderador na relação existente entre os processos de planejamento e a eficácia dos processos de planejamento.

O intuito do planejamento estratégico não é prever o futuro, mas sim construí-lo (FERREIRA et al., 2010; SAMPAIO, 2002). Desta maneira, os processos de planejamento consistem em uma forma de redução das incertezas, que influencia diretamente a tomada de decisão, assim como os resultados, visto que se tem um processo cíclico e constante que implica na possibilidade de trabalhar com a leitura de cenários futuros, como forma de reduzir incertezas e direcionar as organizações (KICH; PEREIRA, 2011; SILVA; GONÇALVES, 
2011; SILVA; MENEGAT; SARMENTO, 2017). A soma dos efeitos diretos e indiretos é referida como o efeito total e sua análise constitui um passo essencial para a interpretação e conclusões. Depois de examinar a importância das relações é fundamental avaliar a relevância, posto que os coeficientes podem ser estatisticamente significantes, mas em relação ao efeito no construto dependente podem ser irrelevantes e não justificam atenção gerencial (HAIR JR. et al., 2017). O efeito total das relações no caminho estrutural é apresentado na Tabela 2.

Tabela 2 Efeito Total

\begin{tabular}{|c|c|c|c|}
\hline Construtos & Efeito Total & Nível de Significância & $\mathbf{p}$ \\
\hline $\mathrm{CPLA} \rightarrow \mathrm{CONC}$ & 0,0700 & $* *$ & 0,0402 \\
\hline $\mathrm{CPLA} \rightarrow \mathrm{EFIC}$ & 0,0934 & $* *$ & 0,0390 \\
\hline $\mathrm{CPLA} \rightarrow \mathrm{OBJT}$ & 0,0475 & $*$ & 0,0932 \\
\hline $\mathrm{CPLA} \rightarrow \mathrm{PLAN}$ & 0,3146 & $* * *$ & 0,0000 \\
\hline $\mathrm{EVEX} \rightarrow \mathrm{CAPC}$ & 0,0634 & $* *$ & 0,0326 \\
\hline $\mathrm{EVEX} \rightarrow \mathrm{CONC}$ & 0,0526 & $*$ & 0,0508 \\
\hline EVEX $\rightarrow$ EFIC & 0,0702 & $* *$ & 0,0342 \\
\hline EVEX $\rightarrow$ OBJT & 0,0357 & $* *$ & 0,0332 \\
\hline EVEX $\rightarrow$ PLAN & 0,2365 & $* * *$ & 0,0000 \\
\hline $\mathrm{EVIN} \rightarrow \mathrm{CAPC}$ & 0,0659 & $* *$ & 0,0349 \\
\hline $\mathrm{EVIN} \rightarrow \mathrm{CONC}$ & 0,0547 & $* *$ & 0,0363 \\
\hline $\mathrm{EVIN} \rightarrow$ EFIC & 0,0730 & $* *$ & 0,0330 \\
\hline $\mathrm{EVIN} \rightarrow \mathrm{OBJT}$ & 0,0371 & $*$ & 0,0777 \\
\hline EVIN $\rightarrow$ PLAN & 0,2458 & $* * *$ & 0,0000 \\
\hline $\mathrm{RECU} \rightarrow \mathrm{CAPC}$ & 0,0454 & $*$ & 0,0591 \\
\hline $\mathrm{RECU} \rightarrow \mathrm{CONC}$ & 0,0377 & $*$ & 0,0801 \\
\hline $\mathrm{RECU} \rightarrow \mathrm{EFIC}$ & 0,0504 & $*$ & 0,0617 \\
\hline $\mathrm{RECU} \rightarrow \mathrm{OBJT}$ & 0,0256 & $*$ & 0,0881 \\
\hline $\mathrm{RECU} \rightarrow$ PLAN & 0,1696 & $* * *$ & 0,0000 \\
\hline $\mathrm{RESI} \rightarrow \mathrm{CAPC}$ & 0,0661 & $* *$ & 0,0481 \\
\hline $\mathrm{RESI} \rightarrow \mathrm{CONC}$ & 0,0549 & $*$ & 0,0526 \\
\hline $\mathrm{RESI} \rightarrow \mathrm{EFIC}$ & 0,0732 & $* *$ & 0,0473 \\
\hline $\mathrm{RESI} \rightarrow \mathrm{OBJT}$ & 0,0372 & NS & 0,1002 \\
\hline RESI $\rightarrow$ PLAN & 0,2466 & $* * *$ & 0,0000 \\
\hline $\mathrm{TECN} \rightarrow \mathrm{CAPC}$ & 0,0570 & $*$ & 0,0840 \\
\hline $\mathrm{TECN} \rightarrow \mathrm{CONC}$ & 0,0473 & NS & 0,1136 \\
\hline $\mathrm{TECN} \rightarrow \mathrm{EFIC}$ & 0,0631 & $*$ & 0,0862 \\
\hline $\mathrm{TECN} \rightarrow$ OBJT & 0,0321 & $*$ & 0,0830 \\
\hline $\mathrm{TECN} \rightarrow \mathrm{PLAN}$ & 0,2126 & $* * *$ & 0,0001 \\
\hline $\mathrm{PLAN} \rightarrow \mathrm{CAPC}$ & 0,2680 & $* *$ & 0,0376 \\
\hline $\mathrm{PLAN} \rightarrow \mathrm{CONC}$ & 0,2226 & $* *$ & 0,0462 \\
\hline PLAN $\rightarrow$ EFIC & 0,2970 & $* *$ & 0,0370 \\
\hline PLAN $\rightarrow$ OBJT & 0,1510 & $*$ & 0,0726 \\
\hline
\end{tabular}




\begin{tabular}{lccc}
\hline Construtos & Efeito Total & Nível de Significância & p \\
\hline FORM $*$ PLAN $\rightarrow$ EFIC & $-0,2511$ & NS & 0,3787 \\
EFIC $\rightarrow$ CAPC & 0,9023 & $* * *$ & 0,0000 \\
EFIC $\rightarrow$ CONC & 0,7494 & $* * *$ & 0,0000 \\
EFIC $\rightarrow$ OBJT & 0,5084 & $* * *$ & 0,0005 \\
\hline
\end{tabular}

$\mathrm{NS}=$ não significante. ${ }^{* * *} \mathrm{p}<0,01 .{ }^{* *} \mathrm{p}<0,05 .{ }^{*} \mathrm{p}<0,10$.

Fonte: Dados da pesquisa.

As características das IES determinam a sua estrutura, funcionamento e o modelo de gestão a ser adotado, principalmente, por estas unidades educacionais serem consideradas organizações complexas pelos seus objetivos, uso diferenciado da tecnologia, presença de grupos com interesses distintos, especificidades de sua clientela, atributos do meio acadêmico e a suscetibilidade de influência dos fatores externos (MEYER JR.; SERMANN; MANGOLIM, 2004; MEYER JR.; MEYER, 2011). A hipótese H2 é suportada neste estudo, pois os consequentes da eficácia, cumprimento dos objetivos do planejamento (H2a; PLAN $\rightarrow$ OBJT $=0,1510 ; \mathrm{p}<0,10$ e EFIC $\rightarrow$ OBJT $=0,5084 ; \mathrm{p}<0,01)$, capacitação do sistema gerencial (H2b; PLAN $\rightarrow$ CAPC $=0,2680 ; p<0,05$ e EFIC $\rightarrow$ CAPC $=0,9023 ; p<0,01)$ e desempenho relativo à concorrência $(\mathbf{H 2 c} ; \mathrm{PLAN} \rightarrow \mathrm{CONC}=0,226 ; \mathrm{p}<0,05$ e EFIC $\rightarrow$ CONC $=0,7494 ; \mathrm{p}<0,01)$ são influenciados positivamente pela eficácia observada em função dos processos de planejamento.

Esses resultados asseguram que a adoção de abordagens de gestão, por exemplo, o planejamento estratégico, tem sido cada vez mais crescente nas IES (MAINARDES; MIRANDA; CORREIA, 2011). A busca por modelos gerenciais que são amplamente utilizados no setor empresarial pode ser atribuída à necessidade de responder ao contexto competitivo em que as IES estão inseridas, à necessidade de se manterem ativas, ao fato de não existir teoria direcionada à gestão universitária, assim como da obrigação de uma administração eficaz, porque a prática da gestão nas IES sofre influência de suas próprias características, que as distingue de outros tipos de organizações (FIDELIS; BARBOSA, 2012; MEYER JR.; PASCUCCI; MANGOLIN, 2012; DIAS; SANTOS; BEIRUTH, 2016; AMARANTE; CRUBELLATE; MEYER JR., 2017).

Os gestores das IES devem ser capazes de compreender e atuar considerando tanto o ambiente interno, quanto o externo, adaptando as ferramentas de gestão que são utilizadas por organizações do mercado (FERREIRA et al., 2010; FIDELIS; BARBOSA, 2012; BALTARU; SOYSAL, 2018). Assim eles estão preparados para tratar de questões que 
ultrapassam o ambiente acadêmico. As relações, sobre o efeito direto e efeito total, se mostraram estatisticamente significantes. A utilização de técnicas de planejamento (TECN $\rightarrow$ PLAN $=0,2126 ; p<0,05$ e TECN $\rightarrow$ EFIC $=0,0631 ; p<0,10)$, a atenção a eventos externos $(\mathrm{EVEX} \rightarrow \mathrm{PLAN}=0,2365 ; \mathrm{p}<0,01$ e EVEX $\rightarrow$ EFIC $=0,0702 ; \mathrm{p}<0,05)$, a atenção a eventos internos $(E V I N \rightarrow$ PLAN $=0,2458 ; p<0,01$ e EVIN $\rightarrow$ EFIC $=0,0730 ; p<0,05)$, os recursos alocados (RECU $\rightarrow$ PLAN $=0,1696 ; p<0,01$ e RECU $\rightarrow$ EFIC $=0,0504 ; p<0,10)$ e a cobertura do sistema de planejamento $(\mathrm{CPLA} \rightarrow \mathrm{PLAN}=0,3146 ; \mathrm{p}<0,01$ e CPLA $\rightarrow$ EFIC $=$ 0,0934; $\mathrm{p}<0,05$ ) influenciam positivamente os processos de planejamento e a eficácia.

As IES, assim como as organizações, devem encontrar o equilíbrio entre a estratégia e a sua estrutura organizacional, sendo que esta relação é contínua (MEYER JR.; PASCUCCI; MANGOLIN, 2012). Com isso, a implementação dos processos de planejamento influencia no agrupamento, funcionamento, execução de tarefas e tomada de decisão, que reciprocamente, associa-se aos objetivos, a capacitação, ao desempenho e a definição de prioridades, enquanto, a implementação do processo de planejamento é uma função hierárquica, para controle, avaliação e regulação do comportamento organizacional (NEIS; PEREIRA, 2014; HEIL; LAUX, 2017). Uma observação é que neste estudo, 19,49\% dos respondentes estão nas IES entre 0 e 2 anos, quiçá, seja pertinente pensar que essas pessoas ainda estejam em fase de socialização e por consequência, sua maturidade e percepção a respeito dos antecedentes dos processos de planejamento possa ser questionada. Não obstante, essa visão a priori distorcida é benéfica para as IES, afinal, o olhar que se põe, as sugestões de aprimoramento, as críticas construtivas, entre outras colaborações apresentadas tendem a ser desprovidas de vícios e acomodações profissionais decorrentes da experiência e atuação na IES por um longo período de tempo.

O planejamento influência e é influenciado por vários fatores organizacionais, como liderança, cultura, estrutura, comunicação e outros, podendo melhorar a integração entre os setores da organização, principalmente, devido ao incentivo à busca por objetivos comuns (KICH; PEREIRA, 2011). Este processo é um instrumento que pode motivar os funcionários, por meio do estabelecimento de metas e monitoramento do desempenho nos diversos níveis da organização. Contudo, o que se observa é que o desdobramento dos planos pode alcançar maior sucesso, quando as organizações levam em consideração as informações das pessoas que estão diretamente envolvidas com a execução dos planos, porque elas tem capacidade de direcionar as ações, cumprir os prazos e alcançar as metas, além de também atuarem na 
geração dos indicadores que permitem acompanhar o desempenho realizado e assim, identificar os ajustes necessários para colocar a IES rumo ao alcance dos seus objetivos (SILVA; GONÇALVES, 2011; ALMEIDA; MENEZES, 2013; CHACON; CALDERÓN, 2015; MARCO; SANTOS; SEHNEM, 2017).

A organização que apresenta resistência ao seu processo de planejamento certamente terá um sistema de planejamento menos eficiente (STEINER, 1991). O aspecto a ser destacado está sobre a questão que se projeta frente a resistência ao planejamento, posto que ela influencia positivamente os processos de planejamento $($ RESI $\rightarrow$ PLAN $=0,2466 ; p<$ $0,01)$ e a eficácia (RESI $\rightarrow$ EFIC $=0,0732 ; \mathrm{p}<0,05)$. Naturalmente, a expectativa sobre o senso comum é de que as IES que tenham processos de planejamento mais eficazes, apresentem menor resistência aos processos de planejamento, porém, os resultados indicam que a resistência ao planejamento, de acordo com a percepção dos respondentes das IES privadas da $\mathrm{RMBH}$, não é prejudicial ao sistema de planejamento e à sua eficácia. Pelo contrário, a resistência ao planejamento tem um efeito positivo nos processos de planejamento. De fato, a eficiência do sistema de planejamento é influenciada pela resistência ao processo de planejamento nas organizações (RAMANUJAM; VENKATRAMAN, 1987; STEINER, 1991), inclusive, de maneira positiva em estudos anteriores (SEGARS; GROVER; TENG, 1998; ESTOLANO, 2002a). Enfim, o contexto competitivo das IES privadas exige que elas revejam suas políticas e práticas de gestão, buscando eficiência na consecução de seus objetivos e obtenção de vantagem competitiva para garantir sua sobrevivência frente aos seus concorrentes (SCHNEIDER, 2013; DIAS; SANTOS; BEIRUTH, 2016).

\section{CONSIDERAÇÕES FINAIS}

O planejamento estratégico é essencial para o sucesso das organizações. Essas não alcançam seus objetivos por acaso, mas sim pelo direcionamento proporcionado pelo uso dos processos de planejamento (ALMEIDA; MENEZES, 2013). O estudo analisou a percepção dos responsáveis pelo planejamento das IES privadas da Região Metropolitana de Belo Horizonte, quanto aos fatores que antecedem o sistema de planejamento e suas dimensões de eficácia. A formalização nas IES não é um moderador da relação existente entre os processos de planejamento e a eficácia destes processos. As características dos processos de planejamento por ordem de maior influência são: a cobertura do sistema de planejamento, a resistência ao planejamento, a atenção a eventos internos, a atenção a eventos externos, a 
utilização de técnicas de planejamento e os recursos alocados no planejamento. Esses processos de planejamento são capazes de explicar aproximadamente $36 \%$ da eficácia, que por sua vez, implica em cerca de $81 \%$ da capacitação do sistema gerencial, em $56 \%$ do desempenho relativo à concorrência e em $26 \%$ do cumprimento dos objetivos do planejamento.

A limitação pode ser observada no fato de a mensuração do grau de formalização ter considerado somente a percepção dos respondentes, assim como, a não estratificação dos resultados entre as IES de maior e menor porte de acordo com a quantidade de cursos de graduação. No mais, as IES possuem estruturas próprias que as distinguem entre si e isso, não foi considerado neste estudo, logo, a indicação é que isto pode influenciar os resultados de negócio individuais das IES, além de também afetar a formalização, percepção e real eficácia final do planejamento. Mesmo assim, os resultados são consistentes e o estudo contribui para a prática da gestão educacional, pois oferece um panorama a respeito dos antecedentes dos processos de planejamento nas IES privadas, além de indicar as características que influenciam os consequentes da eficácia do sistema de planejamento. Na perspectiva acadêmica, o estudo teve a intenção de compreender como se dá a gestão acadêmica em organizações educacionais privadas e por isso, buscou preencher uma parte da lacuna indicada por Meyer Jr., Pascucci e Mangolin (2012), na qual a literatura carece de estudos voltados à formação de estratégias educacionais, principalmente, porque as IES diferem de outros tipos de organizações.

Como indicação para pesquisas futuras, a primeira sugestão, é considerar a formalização como um antecedente dos processos de planejamento, ou mesmo, que este construto possa simultaneamente ser posto como moderador de cada um dos outros antecedentes, uma vez que a utilização de técnicas de planejamento, a atenção a eventos externos, a atenção a eventos internos, os recursos alocados, a resistência ao planejamento e a cobertura do sistema de planejamento, podem ocorrer em maior ou menor grau sobre a questão da formalização de cada um desses processos que constituem a essência do planejamento organizacional. A segunda sugestão, é segmentar a amostra, por exemplo, de acordo com a quantidade de cursos de graduação, logo, ao ter dois ou mais grupos é possível proceder com a análise multi-grupo para comparar as características que constituem a heterogeneidade observada, por fim, o modelo hipotético também pode abranger um conjunto de dados que inclua as IES públicas e privadas. 


\section{REFERÊNCIAS}

ALMEIDA, Antônio A.; MENEZES, Josefa D. F. Importância do planejamento estratégico como fator preponderante ao crescimento organizacional. Revista Eletrônica da Faculdade José Augusto Vieira, v. 6, n. 1, p. 60-76, 2013. Disponivel em: <https://bit.ly/2CLmsc5>.

AMARANTE, Juliana M.; CRUBELLATE, João M.; MEYER JR., Victor. Estratégias em universidades: Uma análise comparativa sob a perspectiva institucional. Revista Gestão Universitária na América Latina, v. 10, n. 1, p. 190-212, 2017.

ARMSTRONG, J. S. The value of formal planning for strategic decisions: Review of empirical research. Strategic Management Journal, v. 3, n. 3, p. 197-211, 1982.

BALTARU, Roxana-Diana; SOYSAL, Yasemin N. Administrators in higher education: Organizational expansion in a transforming institution. Higher Education, v. 76, n. 2, p. 213$229,2018$.

BETHLEM, Agricola D. S. Estratégia empresarial: Conceitos, processo e administração estratégica. 5. ed. São Paulo: Atlas, 2004.

BIELER, Andrew; MCKENZIE, Marcia. Strategic planning for sustainability in Canadian higher education. Sustainability, v. 9, n. 2, p. 161-182, 2017.

CHACON, José M. T.; CALDERÓN, Adolfo I. A expansão da educação superior privada no Brasil: Do governo de FHC ao governo de Lula. Revista Iberoamericana de Educación Superior, v. 6, n. 17, p. 78-100, 2015.

CHAKRAVARTHY, Balaji S.; LORANGE, Peter. Managing the strategy process: A framework for a multibusiness firm. New York: Prentice Hall, 1991.

CHANDLER, Alfred D. Strategy and structure: Chapters in the history of the industrial enterprise. Cambridge: Massachusetts Institute of Technology Press, 1962.

COHEN, Jacob. A power primer. Psychological Bulletin, New York, v. 112, n. 1, p. $155-$ 159, 1992.

DIAS, Alexsandra B.; SANTOS, Valquíria A.; BEIRUTH, Aziz X. Consistência das estratégias de instituições de ensino superior: Um estudo baseado na percepção dos stakeholders utilizando-se do balanced scorecard. Revista de Educação e Pesquisa em Contabilidade, v. 10, n. 4, p. 431-448, 2016.

DRUCKER, Peter F. Administrando em tempos de grandes mudanças. São Paulo: Pioneira, 1998.

ESTOLANO, Alexandre L. D. Processos de planejamento estratégico em empresas brasileiras: Um estudo sobre a sua disseminação e benefícios de sua adoção. 2002a. $248 \mathrm{f}$. Tese de Doutorado - Universidade Federal do Rio de Janeiro (UFRJ), Rio de Janeiro/RJ, 2002a. Disponivel em: $<$ https://bit.ly/2EqGvhz $>$. 
ESTOLANO, Alexandre L. D. Uma avaliação da eficácia dos processos de planejamento estratégico em empresas brasileiras: Um estudo sobre a percepção dos benefícios de sua adoção. In: ENCONTRO NACIONAL DOS PROGRAMAS DE PÓS-GRADUAÇÃO EM ADMINISTRAÇÃO, 26., 2002, Salvador. Anais... Rio de Janeiro: ANPAD, 2002 b.

ESTRADA, Rolando J. S.; ALMEIDA, Martinho I. R. D. A eficiência e a eficácia da gestão estratégica: do planejamento estratégico à mudança organizacional. Revista de Ciências da Administração, v. 9, n. 19, p. 147-178, 2007. Disponivel em: <https://bit.ly/2PHmDYU>.

FARINHA, C.; AZEITEIRO, Ulisses M.; CAEIRO, Sandra. Education for sustainable development through policies and strategies in the public Portuguese higher education institutions. In: LEAL FILHO, Valter; AZEITEIRO, Ulisses M.; ALVES, Fátima;

MALTHAN-HILL, Petra Handbook of theory and practice of sustainable development in higher education. Cham, Switzerland: Springer, v. 4, 2017. p. 275-290.

FAUL, Franz; ERDFELDER, Edgar; BUCHNER, Axel; LANG, Albert-Georg. Statistical power analyses using $\mathrm{G}^{*}$ Power 3.1: Tests for correlation and regression analyses. Behavior Research Methods, v. 41, n. 4, p. 1149-1160, 2009.

FERREIRA, Marcus V. A.; SERRA, Fernando A. R.; FERREIRA, Manuel P.; SANTOS, Neri D. Planejamento estratégico participativo em uma instituição de ensino superior (IES) comunitária. Estratégia e Negócios, v. 3, n. 1, p. 28-52, 2010.

FIDELIS, Joubert R. F.; BARBOSA, Ricardo R. A competência informacional e sua influência na percepção de variáveis organizacionais estratégicas em IES privadas.

Perspectivas em Gestão e Conhecimento, v. 2, n. Especial, p. 27-39, 2012. Disponivel em: $<$ https://bit.ly/2Orelrf $>$.

HAIR JR., Joseph F.; HULT, G. T. M.; RINGLE, Christian M.; SARSTEDT, Marko. A primer on partial least squares structural equation modeling (PLS-SEM). 2. ed. Thousand Oaks: Sage, 2017.

HEIL, Gissele P.; LAUX, Raul O. Planejamento e gestão estratégica nas IES comunitárias. Revista Gestão Universitária na América Latina, v. 10, n. 1, p. 115-133, 2017.

HENSELER, Jörg; HUBONA, Geoffrey; RAY, Pauline A. Using PLS path modeling in new technology research: Updated guidelines. Industrial Management \& Data Systems, v. 116, n. 1, p. 2-20, 2016.

HITT, Michael A.; IRELAND, R. D.; PALIA, K. A. Industrial firms' grand strategy and functional importance: Moderating effects of technology and uncertainty. Academy of Management Journal, v. 25, n. 2, p. 265-298, 1982.

HU, Juan L. H.; CHEN, Yingxia; QIN, Jiali. Strategic planning and the stratification of Chinese higher education institutions. International Journal of Educational Development, v. in press, p. 1-8, 2017. 
IBGE. Estimativas da população residente no Brasil e unidades da federação com data de referência em $1^{\mathbf{0}}$ de julho de 2018. 2018. Diretoria de Pesquisas - DPE - Coordenação de População e Indicadores Sociais - COPIS, Brasília, 2018. Disponivel em:

$<$ http://www.ibge.gov.br/>.

KICH, Juliane I. D. F.; PEREIRA, Maurício F. A influência da liderança, cultura, estrutura e comunicação organizacional no processo de implantação do planejamento estratégico.

Cadernos EBAPE.BR, v. 9, n. 4, p. 1045-1065, 2011.

LEIDECKER, Joel K.; BRUNO, Albert V. Identifying and using critical success factors.

Long Range Planning, v. 17, n. 1, p. 23-32, 1984.

LORANGE, Peter. Formal planning systems: Their role in strategy implementation. In:

SCHENDEL, Dan; HOFER, Charles W. Strategic management: A new view of business policy and planning. Boston: Little, Brown \& Co., 1979. p. 226-241.

MAINARDES, Emerson W.; MIRANDA, Cristina S.; CORREIA, Carlos H. A gestão estratégica de instituições de ensino superior: Um estudo multicaso. Revista Contemporânea de Economia e Gestão, v. 9, n. 1, p. 19-32, 2011.

MARCO, Ricardo A. D.; SANTOS, Gleberson D. S. D.; SEHNEM, Simone. Como ocorre o processo de formação de estratégias em instituições de ensino superior? Um estudo em Santa Catarina. Revista Ibero-Americana de Estratégia, v. 16, n. 3, p. 69-89, 2017.

MEC. Instituições de educação superior e cursos cadastrados. Ministério da Educação. Sistema e-MEC, 2017. Disponivel em: <http://emec.mec.gov.br/>. Acesso em: 05 janeiro 2017.

MEYER JR., Victor; MEYER, Bernardo. Managerialism na gestão universitária: Dilema dos gestores de instituições privadas. In: ENCONTRO NACIONAL DOS PROGRAMAS DE PÓS-GRADUAÇÃO EM ADMINISTRAÇÃO, 35., 2011, Rio de Janeiro. Anais... Rio de Janeiro: ANPAD, 2011.

MEYER JR., Victor; PASCUCCI, Lucilaine; MANGOLIN, Lúcia. Gestão estratégica: Um exame de práticas em universidades privadas. Revista de Administração Pública, v. 46, n. 1, p. 49-70, 2012.

MEYER JR., Victor; SERMANN, Lúcia I. C.; MANGOLIM, Lúcia. Planejamento e gestão estratégica: Viabilidade nas IES. In: COLÓQUIO INTERNACIONAL SOBRE GESTÃO UNIVERSITÁRIA NA AMÉRICA DO SUL, 4., 2004, Florianópolis. Anais... Florianópolis: UFSC, 2004.

MINTZBERG, Henry; LAMPEL, Joseph; QUINN, James B.; GHOSHAL, Sumantra. O processo da estratégia: Conceitos, contexto e casos selecionados. 4. ed. Porto Alegre: Bookman, 2005.

NEIS, Dyogo F.; PEREIRA, Maurício F. O processo de planejamento estratégico e a estrutura organizacional: Impactos, confluências e similaridades. In: ENCONTRO 
NACIONAL DE PROGRAMAS DE PÓS-GRADUAÇÃO EM ADMINISTRAÇÃO, 38., 2014, Rio de Janeiro. Anais... Rio de Janeiro: ANPAD, 2014.

OLIVEIRA, Ronielton R.; MARINHO, Marlon F. A.; DIAS, Alexandre T. Um estudo sobre a utilização da modelagem de equações estruturais na produção cientifica nas áreas de administração e sistemas de informação. Revista de Administração da UFSM, v. 9, n. 4, p. 559-578, 2016.

PARANJAPE, Bhagyashree; ROSSITER, Margaret; PANTANO, Victor. Performance measurement systems: Successes, failures and future-a review. Measuring Business Excellence, v. 10, n. 3, p. 4-14, 2006.

PORTER, Michael E. Competitive strategy: Techniques for analyzing industries and competitors. New York: Free Press, 1980.

PORTER, Michael E. Estratégia competitiva: Técnicas para análise de indústrias e da concorrência. 17. ed. Rio de Janeiro: Campus, 1986.

RAMANUJAM, Vasudevan; VENKATRAMAN, Niloufer. Planning system characteristics and planning effectiveness. Strategic Management Journal, v. 8, n. 5, p. 453-468, 1987.

RAMANUJAM, Vasudevan; VENKATRAMAN, Niloufer; CAMILLUS, John C. Multiobjective assessment of effectiveness of strategic planning: A discriminant analysis approach. Academy of Management Journal, v. 29, n. 2, p. 347-372, 1986.

RINGLE, Christian M.; WENDE, Sven; BECKER, Jan-Michael. SmartPLS 3. Bönningstedt: SmartPLS GmbH, 2015. Disponivel em: <http://www.smartpls.com>.

SAMPAIO, Helena. Planejamento estratégico. Porto Alegre: SEBRAE/RS, 2002.

SANTOS, Valdeci F. D. Planejamento em instituições de ensino superior privadas da região metropolitana de Belo Horizonte: Um estudo sobre a eficácia de sua adoção. 2017. 127 f. Dissertação de Mestrado - Universidade FUMEC, Belo Horizonte/MG, 2017. Disponivel em: $<$ https://bit.ly/2pT7BDM>.

SAUROMBE, Musa; BARKHUIZEN, Nicolene; SCHUTTE, Nico. Management perspectives on a talent value proposition for academic staff in a South African higher education institution. In: DELENER, N.; SCHWEIKERT, Christina Changing business environment: Gamechangers, opportunities and risks. Vienna, Austria: Global Business and Technology Association, 2017. p. 886-894.

SCHNEIDER, Luis C. Pensamento estratégico organizacional: Origens, evolução e principais influências. In: ENCONTRO DE ESTUDOS EM ESTRATÉGIA, 6., 2013. Bento Gonçalves. Anais... Rio de Janeiro: ANPAD, 2013.

SEGARS, Albert H.; GROVER, Varun; TENG, James T. C. Strategic information systems planning: Planning system dimensions, internal coalignment, and implications for planning effectiveness. Decision Sciences, v. 29, n. 2, p. 303-341, 1998. 
SEMESP. Mapa do ensino superior no Brasil 2015. 2015. São Paulo, 2015. Disponivel em: $<$ http://www.semesp.org.br/pesquisas/mapa-do-ensino-superior-2015/>.

SEMESP. Mapa do ensino superior no Brasil 2016. 2016. São Paulo, 2016. Disponivel em: $<$ http://www.semesp.org.br/pesquisas/mapa-do-ensino-superior-2016/>.

SEMESP. Mapa do ensino superior no Brasil 2017. 2017. São Paulo, 2017. Disponivel em: $<\mathrm{http}$ :/www.semesp.org.br/pesquisas/mapa-do-ensino-superior-2017/>.

SILVA, Flávia D. A.; GONÇALVES, Carlos A. O processo de formulação e implementação de planejamento estratégico em instituições do setor público. Revista de Administração da UFSM, v. 4, n. 3, p. 458-476, 2011.

SILVA, Renato; MENEGAT, Jardelino; SARMENTO, Dirléia F. Business model canvas: Contribuições para a gestão estratégica das instituições de ensino superior privadas. Gestão Contemporânea, v. 19, n. 1, p. 25-41, 2017.

SILVA, Sabrina L. C. D.; VIEIRA, Letícia C.; SILVA, Everson P. D. Implementing strategic planning, performance evaluation and process management in higher education institutions. Independent Journal of Management \& Production, v. 8, n. 2, p. 362-377, 2017.

STEINER, George A. Planificación de la alta dirección. Navarra: EUNSA, v. 2, 1991.

TERENCE, Ana C. F. Planejamento estratégico como ferramenta de competitividade na pequena empresa. 2002. 238 f. Tese de Doutorado - Universidade de São Paulo (USP), São Paulo/SP, 2002. Disponivel em: < https://bit.ly/2Eoezef $>$.

VELIYATH, Rajaram. Strategic planning: Balancing short-run performance and longer term prospects. Long Range Planning, v. 25, n. 3, p. 86-97, 1992.

VIZEU, Fabio; GONÇALVES, Sandro A. Pensamento estratégico: Origens, princípios e perspectivas. São Paulo: Atlas, 2010. 